\title{
Cautious welcome for FDA pharmacogenomics guidance
}

The US Food and Drug Administration (FDA) on March 22 issued the long-awaited final version of its Guidance for Industry on submission of pharmacogenomics data, giving industry a strong political signal that it is open to applications concerning therapeutic products 'personalized' to patients' genetic blueprints. The main challenge for the regulator is to encourage industry to submit voluntary data to help refine the pharmacogenomics approval process and speed up the arrival of the next wave of such products to the market.

Industry experts have enthusiastically embraced the new document, calling it an "important first 을 step" for bringing pharmacogenomics-based drugs to market.

"I applaud the FDA for taking the step," says Donald Halbert, executive vice president of R\&D of Iconix Pharmaceuticals in Mountain View, California. "They have maybe intentionally put pressure on themselves to develop the infrastructure, tools and training to work with these kinds of data sets."

The guideline outlines the circumstances under which companies are required to submit pharmacogenomics data and the procedures for submitting them. Data must be submitted when they are based on valid biomarkers that have been rigorously tested by the scientific community and explicitly affect how trials for a product are designed. Using several examples, the document also defines a second category of data as those obtained under the auspices of exploratory research. Data in this latter category do not have to be submitted; instead, the agency encourages companies to submit it voluntarily and in turn promises not to use it to make regulatory decisions.

The document's main impact, says Brian Spear, director of pharmacogenomics at Abbott Laboratories in Abott Park, Illinois, is on reassuring companies that conducting early-stage pharmacogenomic experiments will not bring negative regulatory consequences. "This has been a real worry," says Spear. "In the past companies have avoided generating this data. But I'm guessing that the risk has been so removed by this guidance that this is not going to be an issue."

Pharmacogenomics involves identifying biomarkers, genes that determine a patient's drug metabolism risk for a specific disease, drug metabolism or potential to respond to a specific therapy. The guidance document defines what the agency considers a valid biomarker, but what remains to be fleshed out is the process by which biomarkers come to be validated by the agency and the scientific community. If a company is working with an experimental marker for which it has not been required to submit data, says Donna Mendrick, vice president of toxicogenomics at Gene Logic in Gaithersburg, Maryland, "the concern is that next year the FDA will come to you and say it's valid. Companies want to know, is there a list of valid biomarkers? How do we get our hands on it?"

Although there are a few drugs to be approved on the basis of pharmacogenomics data—such as Herceptin (trastuzumab) first approved in 1998 in the US and since followed by Gleevec (imatinib) and Erbitux (cetuximab) - there hasn't been that many more since. Because the science is still so new, establishing the guidelines will be an evolving process. The document incorporates many suggestions from the Washington-based Biotechnology Industry Organization (BIO).

And further refinement is expected. The FDA on March 28 released a draft concept paper on codeveloping gene-based diagnostics and therapeutics and are planning to publish another one on the role of DNA in microarrays. In October, an agency committee, of which Mendrick is a member, is scheduled to discuss biomarker validation.
To build the knowledge base necessary to scientifically validate new biomarkers and create the needed regulatory infrastructure, industry will have to take up the FDA's request of submitting voluntary genomics data. But how quickly this trend will catch on remains to be seen, experts say. In the past year, the agency has received only about five to ten voluntary data submissions-surprisingly few, says Spear.

To some extent, notes Mendrick, the low number of submissions may reflect a time lag_-provisions for submitting voluntary data were only announced a year and a half ago in the draft version of the guidance document, published in November 2003, and completing the studies necessary to submit an Investigational New Drug application often takes longer than that.

But companies may simply not yet be willing to embrace voluntary submissions, experts say. "There's still a belief [among companies] that if this is voluntary, why jump if we don't have to?" says Spear. "The FDA has really tried to come up with reasons, but those reasons are more relevant for people generating the science" than those on the commercial end, he says. "I think different companies will have different levels of eagerness."

What could entice companies to submit their data, Spear suggests, is evidence that they are benefiting from the process-for example, by gaining credibility with the FDA, or by educating the agency early on about techniques and issues relevant to their product. According to Carol Reed, vice president of medical affairs at New Haven-based Genaissance, one of the few companies who have submitted voluntary genomics data, sitting down to a detailed informal discussion with the agency did in fact have very real benefits. "They had very good questions, they'd done their homework, and they were very helpful to us scientifically," she said.

All recognize that managing the expected volume of data will be a challenge as data acquisition and analysis could bog the FDA officials down, perhaps even draining resources from regulatory review. "Part of the problem for the FDA is, how much data do they want?" says Mendrick. "It's going to add quite a bit of work to their plate."

Alla Katsnelson, New York 